\title{
4-6 Yaş Çocuklarında Kaynak Dağıtımında Eşitsizlikten Kaçınmayı Etkileyen Faktörlerin İncelenmesi
}

\section{Investigation of Factors Affecting Inequality Aversion In Resource Distribution In 4-6 Year Old Children}

\author{
Ezgi Acun ${ }^{1}$ (1), Sema Karakelle ${ }^{2}$ (1)
}

Bu makale, ilk yazarın ikinci yazar danışmanlığında İstanbul Üniversitesi Sosyal Bilimler Enstitüsü Psikoloji Anabilim Dalı'nda tamamlamıs olduğu yüksek lisans tezinden üretilmiştir.

${ }^{1}$ Araş. Gör., İstanbul Üniversitesi, Edebiyat Fakültesi, Psikoloji Bölümü, İstanbul, Türkiye ${ }^{2}$ Doç. Dr., İstanbul Üniversitesi, Edebiyat Fakültesi, Psikoloji Bölümü, İstanbul, Türkiye

ORCID: E.A. 0000-0002-8449-4540 S.K. 0000-0002-3899-6670

\section{Sorumlu yazar/Corresponding author:}

Ezgi Acun,

İstanbul Üniversitesi, Edebiyat Fakültesi, Psikoloji Bölümü, İstanbul, Türkiye

E-posta/E-mail: ezgi.acun@istanbul.edu.tr

Başvuru/Submitted: 19.11.2018

Revizyon Talebi/Revision Requested: 08.02.2019

Son Revizyon/Last Revision Received: 04.04.2019

Kabul/Accepted: 15.04 .2019

Online Yayın/Published Online: 11.06.2019

Atıf/Citation: Acun, E., \& Karakelle, S. (2019). 4-6 yaş çocuklarında kaynak dağıtımında eşitsizlikten kaçınmayı etkileyen faktörlerin incelenmesi. Psikoloji Çalışmaları - Studies in Psychology, 39(1): 99-119.

https://doi.org/10.26650/SP2018-0034

\section{öz}

$\mathrm{Bu}$ çalışmanın amac1, okul öncesi çocuklarda ortak iş yapma, eşitsizlik türü ve bedellilik koşulu faktörlerinin kaynak dağıtımında eşitsizlikten kaçınma üzerindeki etkilerini incelemektir. Bu amaçla çalışmaya 50-72 ay (Ort. 62 ay) arasında olan toplam 80 (39 erkek, 41 kız) çocuk katılmıştır. Çalışma, iki deney ve bir kontrol grubundan oluşmaktadır. Deney gruplarından biri tam ortak iş yapmayı, diğeri yarı ortak iş yapmayı içermektedir. Çocuklarda eşitsizlikten kaçınmayı ölçmek için seçime zorlama oyunu kullanılmış, çocukların partnerleri ile arasında eşitsizliğin ve eșitliğin olduğu dağıtım seçeneklerinden hangisini daha çok tercih ettiğine bakılmıştır. Seçime zorlama paradigması ile eşitsizlikten kaçınmanın eşitsizlik türü ve bedellilik koşulu tarafından nasıl etkilendiğine bakılmıştır (Sheskin, Bloom ve Wynn, 2014). Bedellilik koşulu, çocuğun kendi kaynağının eşitliğin ve eşitsizliğin olduğu dağııı seçeneklerinde aynı sayıda olup olmamasını ifade etmektedir. Eşitsizlik türü ise eşitsizliğin olduğu dağıtım seçeneklerinin dezavantajlı ya da avantajlı olmasını ifade etmektedir. Dezavantajlı eşitsizlik, bir kişinin dağıtımda diğerine göre daha az alma durumu; avantajl eşitsizlik ise bir kişinin dağıtımda diğerine göre daha fazla alma durumu olarak tanımlanmaktadır (Fehr ve Schmidt, 1999). Analizler için karışık model ANOVA kullanılmış, ortak iş yapma gruplar arası faktör, eşitsizlik türü ve bedellilik koşulu ise grup içi faktör olarak değerlendirilmiștir. Bulgular, ilgili literatüre zıt olarak ortak iş yapmanın eşitsizlikten kaçınma üzerinde anlamlı bir etkisinin olmadığını ve çocukların avantajlı eşitsizlik türünde dezavantajlıya göre eşitsizlikten daha fazla kaçındığını göstermektedir. Ayrıca bedellilik koșulunun eşitsizlikten kaçınma üzerinde anlamlı bir etkisinin olduğu, kaynak dağııımları bedelsiz olduğunda bedelli olduğu duruma göre çocukların eşitsizlikten daha fazla kaçındığı görülmüştür. Sonuçların, bu yaş çocuklarında genel-evrensel bir eşitsizlikten kaçınma prensibini desteklemediği söylenebilir.

Anahtar Kelimeler: Kaynak dağıtımı, eșitsizlikten kaçınma, ortak iş yapma 


\section{ABSTRACT}

The aim of this study was to investigate the effects of collaboration, inequality type and cost on inequality aversion in resource distribution in preschool children. With this aim, 80 (39 boys, and 41 girls) children between 50-72 months ( $M=62$ months) old took part in the study. There were two experimental groups and one control group in the study. In one of the experimental groups, there was full collaboration and in the other, there was half collaboration. The forced choice paradigm was used to measure inequality aversion and it was also determined whether equal distribution options between children and their partners were chosen by participants more than unequal ones. Using the forced choice paradigm, the way in which inequality aversion was influenced by inequality type and cost was explored (Sheskin, Bloom \& Wynn, 2014). Cost refers to is whether the participant child's own resource has the same number of equal and unequal distribution options in the game. Inequality type refers to unequal distribution options in the game being either disadvantageous or advantageous. Disadvantageous inequality is the situation where someone receives less than the partner whereas advantageous inequality is the situation where someone receives more than their partner (Fehr \& Schmidt, 1999). Mixed model ANOVA was used for data analysis. Collaboration was treated as a between-subjects factor and inequality type and cost were treated as within-subject factors. The findings show (inconsistent with currently available literature), that there is no significant effect of collaboration on inequality aversion and children show more inequality aversion in the advantageous inequality type than the disadvantageous type. Furthermore, it was found that cost has a significant effect on inequality aversion and children show more inequality aversion in no-cost distributions than cost ones. The results do not appear to support a general-universal inequality aversion principle in this age group.

Keywords: Resource distribution, inequality aversion, collaboration

\section{EXTENDED ABSTRACT}

The distribution of resources can either be equal or unequal between two or more people. In previous literature, unequal distributions have been examined from two perspectives: disadvantageous inequality and advantageous inequality. Disadvantageous inequality is defined as a situation where one person receives less resources than another person. Advantageous inequality is defined as a situation where one person receives more resources than another person. Inequality aversion is defined as a preference for equality rather than inequality in resources distribution. According to Fehr and Schmidt (1999), adults are willing to sacrifice their own rewards in order to prevent inequality both when they receive less than a partner and when they receive more than a partner.

In the literature concerning developmental psychology, the findings indicate that, opposite to adults, preschool children are willing to sacrifice their own resources in order to prevent inequality when they receive less than a partner but not when they receive more than a partner. So they show disadvantageous inequality aversion but not advantageous inequality aversion (Fehr, Bernhard \& Rockenbach, 2008; LoBue, Nishida, Chiong, Deloache, \& Haidt, 2011; Moore, 2009). By way of an explanation for these findings, some researchers say that preschool children do not want to be disadvantaged and want to be advantaged in social comparison processes because they feel social emotions such as envy (disadvantageous inequality) and schadenfreude (advantageous inequality) and yet they can't regulate these 
social emotions well (Sheskin, Bloom, \& Wynn, 2014). When they become 8-9 years old, they can regulate these social emotions and show inequality aversion for both inequality types. Some researches say that these findings don't necessarily indicate immaturity of skills due to age, but they can be explained with the experimental conditions in the researches (Blake, Mcauliffe, \& Warneken, 2014). In certain conditions, the participant child's partner is not present or the participant child receives resources without doing any work - a windfall effect - or the child is forced to choose one of the pre-defined distributions. There are some findings that preschool children can show advantageous inequality aversion when the experimental conditions are changed. For example, it was found that when children collaborate, even if the distribution was set to create advantageous inequality by the researchers, 3-year-olds equalized themselves and their partners by giving them their extra resource(s) (Hamann, Warneken, Greenberg, \& Tomasello, 2011; Warneken, Lohse, Melis, \& Tomasello, 2011). It might show that collaboration is important for inequality aversion, especially for the advantageous one. Tomasello, Melis, Tennie, Wyman and Herrmann (2012) say that behaviours such as equal sharing, helping and other related skills were formed in the process of collaboration and they call it interdependence hypothesis. Thus, one of the aims of this study is to investigate the effect of collaboration on inequality aversion in line with the interdependence hypothesis. Other aims are to investigate the effects of inequality type and cost (to be willing to sacrifice one's own resource) on inequality aversion.

Warneken et al. (2011) suggested that the forced choice paradigm would make inequality aversion difficult because of pre-defined conditions but the present study doesn't agree with this idea. If collaboration is a facilitator factor in inequality aversion, it may also be valid for the forced-choice paradigm. As far as is known, there is no research that has investigated the effect of collaboration using the forced choice paradigm.

\section{Method}

The participants were made up of 80 (39 male, 41 female) children aged between 50-72 months $(M=62, S D=5.99)$ who were attending kindergartens in Istanbul. The experimental groups had 27 participants and the control group had 26 participants.

The research was experimental and the experimantal groups were designed in two ways: full and half collaboration. For the collaboration element, bead and box game was used (in this game, the beads were put into boxes according to color) and for inequality aversion, a forced choice game (there were two options which included equal and unequal distributions between the child and the partner and the child was forced to choose one of these two options) was used. In these games the child's partner was a hand puppet named "Bibo" and the rewards for the games were gender neutral stickers. Each child was tested individually. 
The forced-choice game included four distributions, meaning that each one had an equal and an unequal (disadvantageous or advantageous) option. Both disadvantageous and advantageous options had cost (the child received a different number of rewards depending on whether they chose the equal or unequal option) and non-cost (the child received the same number of rewards irrespective of whether they chose the equal or unequal option) distributions (Sheskin, Bloom, \& Wynn, 2014). Thus, the distributions were like "costly disadvantageous", "non-costly disadvantageous", "costly advantageous", "non-costly advantageous". Each participant child received"1"for equal options and "0" for unequal options.

\section{Results}

In the results, a $3 \times 2 \times 2$ mixed model ANOVA with inequality type (disadvantageous, advantageous) and cost (cost, no cost) as within-subject factors and collaboration (full collaboration, half collaboration, no collaboration) as a between-subjects factor, was performed with the number of egalitarian choices as the dependent variable. Between subjects, it was observed that there was no significant main effect from collaboration, $(F(2,77)$ $\left.=0.25, p=0.78, \eta_{p}^{2}=.01\right)$. Within subjects, there was a significant main effect from inequality type, $\left(F(1,77)=6.18, p=.02, \eta_{p}{ }^{2}=.07\right)$ with more egalitarian decisions overall in advantageous trials $(M=1.15, S D=0.64)$ compared to disadvantageous trials $(M=0.90, S D=0.67)$. Within subjects, there was a significant main effect from cost, $\left(F(1,77)=7.25, p=0.01, \eta_{p}{ }^{2}=.09\right)$ with more egalitarian decisions overall in no cost trials $(M=1.19, S D=0.71)$ compared to cost trials $(M=0.86, S D=0.73)$. There was no interaction effect.

\section{Discussion}

Consequently, this research may add new problems to the literature with the findings that collaboration doesn't affect inequality aversion which is inconsistent with the interdependence hypothesis. Also the findings indicate that children show advantageous inequality aversion more than disadvantageous one which is inconsistent with the idea that preschool children can't regulate social emotions well. Furthermore, cost has an important effect on children's equality preferences and children show more inequality aversion in nocost distributions than cost ones. This finding is not consistent with the inequality aversion model (Fehr \& Schmidt, 1999) which indicates that people are willing to sacrifice their own resources to prevent inequalities. Although there are some limitations in the study, this research suggests that inequality aversion in preschoolers might not be rigid (developmentally, first disadvantageous aversion and later advantageous aversion or collaboration is essential for inequality aversion) rather, it could be a flexible behavior. 
Kaynak dağıtımları, insanlar arasında eşit ve eşit olmayan biçimlerde yapılabilir. Eşitliğin ve eşitsizliğin olduğu kaynak dağıtımlarına verilen tepkiler, sosyal psikoloji, gelişimsel psikoloji, davranışsal ekonomi gibi farklı disiplinler tarafından incelenen bir konu olmuştur. Konuyla ilgili ilk çalışmalara sosyal psikoloji alanında rastlanmaktadır. Festinger (1954), bireylerin mevcut durumunu diğer kişilere göre değerlendirdiği sosyal karş1laştırma yapma gibi bir eğilimleri olduğundan bahseder. Adams (1965), bireylerin eşitsizlik algıladıklarında kendi kazançlarını değiştirme, içinde bulundukları durumu terk etme, karşılaştırma olarak referans aldıkları kişiyi değiştirme ve kendisinin ya da partnerinin kazancını bilişsel olarak çarpıtma gibi tepkiler gösterdiğini belirtmektedir. Fehr ve Schmidt ise (1999), eşitsizliğin olduğu dağıtımlara davranışsal tepki gösterildiğini ve bu tepkinin eşit olmayan dağıtımı eşit hale getirmek şeklinde olabildiğini belirtmektedirler. Katkı, ihtiyaç veya hak etme gibi ölçütler söz konusu olmadığı zaman insanlar, kendileri ve diğerleri arasındaki eşit dağıtımları eşitsiz olan dağıtımlara göre daha çok tercih ediyor görünmektedir (Loewenstein, Thompson ve Bazerman, 1989). Hatta bireylerin, eşitsizliğin olduğu dağıtımlarda eşitliğin olduğu dağıtımlara göre daha fazla kazanç elde etmelerine rağmen, eşitsizlikten kaçınan tercihlerde bulunma eğiliminde oldukları görülmüştür (McAuliffe, Blake, Kim, Wrangham ve Warneken, 2013). İnsanların bu eğilimlerini açıklamak üzere, davranışsal ekonomi alanındaki araştırmacılar tarafından Eşitsizlikten Kaçınma Modeli (Model of Inequity Aversion) öne sürülmüştür (Fehr ve Schmidt, 1999). Bu modele göre insanlar sosyal varlıklardır ve kendi kazançlarının miktarını olduğu kadar kazançlarının diğerininkine göre daha az ya da fazla olup olmamasını da önemserler. Modele göre, insanlar bir diğeri ile aralarında eşitsizlik olduğunda, eşitsizliğe karşı bir direnç ya da tepki göstermekte ve eşit olmayan sonuçları eşite yaklaştırabilmek için kaynaklarından feragat etmeye gönüllü davranmaktadır (Fehr ve Schmidt, 1999). Hedtvedt (2006), insanların kaynak dağıtımlarının adil yapılmadığını düşündüklerinde duygusal, bilişsel ve davranışsal bir dizi tepki verdiğini belirtmektedir.

Eşit olmayan kaynak dağıtımları dezavantajlı ve avantajlı eşitsizlik olmak üzere iki ayrı türde incelenmektedir. Dezavantajlı eşitsizlik, bir kişinin dağıtımda diğerine göre daha az alma durumu; avantajlı eşitsizlik ise bir kişinin dağıtımda diğerine göre daha fazla alma durumu olarak tanımlanmaktadır (Fehr ve Schmidt, 1999). Yedi ve sekiz yaş çocuklarıyla (Blake ve Mcauliffe, 2011; Sheskin, Bloom ve Wynn, 2014) yapılan araştırmalar, bu yaş çocuklarının dezavantajlı ve avantajlı oldukları eşitsizlik durumuna tepki gösterdiklerini ve iki tür eşitsizlik karşısında da eşit kaynak dağıtımlarını tercih ettik- 
lerini ortaya koymuştur. Okul öncesi dönem çocukları ile yapılan araştırmalar, bu çocukların dezavantajı eşitsizlik karşısında duygusal ve davranışsal birtakım tepkiler verdiklerini belirtmektedir. Örneğin, bir araştırmada okul öncesi çocukların eşitsizlik durumunda yüz ifadeleri kodlanmış, 3 yaş çocuklarının dezavantajlı eşitsizliğin olduğu dağıtım karşısında üzgün göründüğü bulunmuştur (LoBue, Nishida, Chiong, Deloache ve Haidt, 2011). Eğer dezavantajlı eşitsizliği düzeltme, eşit duruma getirebilme söz konusu ise, okul öncesi çocuklar bunu yapmak için eşitsizlik durumunda kendi alacağ1 daha fazla olmasına rağmen eşitliği tercih etme gibi kaynaklarından feragat etme davranışlarında bulunabilmektedirler. Örneğin, 5-10 yaş çocuklarıyla yapılan bir araştırmada, çocuklarla biri eşitliğin diğeri de dezavantajlı eşitsizliğin olduğu iki farklı dağıtım koşulu sunularak bu iki koşuldan birini tercih etmesi istenen oyun oynanmıştır. Sunulan (1/1-2/3) dağıtım koşullarından birini tercih etmesi istendiğinde, (bu oyunda çocuk ya kendisinin 2, diğerinin 3 aldığ sında fark olmaksızın bütün çocukların (2/3) koşulunda (kendisinin 2, diğerinin 3 ald1ğ1) dezavantajlı olmak yerine (1/1) koşulunu (kendisinin 1 , diğerinin 1 aldığ 1 ) yani eşit dağıtımı daha çok tercih ettikleri bulunmuştur (Sheskin, Bloom ve Wynn, 2014). Eşitsizlikten kaçınma modeli (Fehr ve Schmidt, 1999) ile tutarlı bir biçimde, dezavantajlı eşitsizliğin olduğu dağıtımda eşitliğin olduğu dağıtıma göre kendisi için daha fazla kaynak olmasına rağmen çocukların tercihini eşitlikten yana kullandığı, yani eşitsizlikten kaçınmak için kendi kaynaklarından feragat edebildikleri görülmüştür. Okul öncesi çocukların avantajlı eşitsizlik karşısındaki tepkileri de incelemiş ve 3 yaş çocuklarının dezavantajlı eşitsizlikte üzgün göründüğü çalışmada, avantajlı eşitsizlik olduğunda üzgün görünmediği bulunmuştur (LoBue ve ark., 2011). Ayrıca 5-6 yaş çocukları, avantajlı eşitsizlikten kaçınmak için dezavantajlı eşitsizlikte yaptıkları gibi kaynaklarından feragat etmemekte üstelik avantajlı eşitsizlik durumunu tercih etmek için kaynaklarından feragat etmektedirler. Nitekim, sunulan (1/0-2/2) dağıtım koşullarından birini tercih etmesi istendiğinde, 5-6 yaş çocuklarının (1/0) koşulunu (kendisinin 1, diğerinin 0 aldı ğ eşit koşula (2/2) göre daha çok tercih ettikleri ve bu tercihin yaşla birlikte azalarak daha büyük çocukların (7-10 yaş arası) eşit koşulu (2/2) daha çok tercih ettikleri bulunmuştur (Sheskin, Bloom ve Wynn, 2014). Sonuç olarak bu araştırmalara göre kaynak dağıtımında eşitsizlik halinde büyük çocuklar ve küçük çocukların farklı tepkiler verdikleri veya farklı tercihlerde bulundukları görülmektedir. Bulgulara göre, dezavantajlı eşitsizlikten kaçınma, okul öncesi dönem çocuklarında avantajlı eşitsizlikten kaçınmaya göre daha fazla görülmekte iken 7-8 yaşlarında iki eşitsizlik türünden de kaçınma görülmek- 
tedir. Yaşa bağlı bu farklılığı açıklamaya çalışan araştırmacılardan bazıları bu durumu küçüklerin duygularını düzenlemesi ile ilgili sınırlılıklarıyla açıklamaktadır. Dezavantajlı eşitsizlikte diğerine göre daha az kazanç elde edilmesi kıskançlığa (Williams ve Moore, 2014); avantajlı eşitsizlikte diğerine göre daha fazla kazanç elde edilmesi ise, çekememezlik veya haset duyulmasına neden olabilir ve bu duygular her iki eşitsizlikten kaçınma davranışı ile ilişkili olabilir (Steinbeis ve Singer, 2013). Okul öncesi çocuklar sosyal karşılaştırmaya daha duyarlı oldukları için, diğerine göre daha çok kazanmayı diğerine göre daha az kazanmaya tercih ediyor veya daha prestijli buluyor olabilirler. Henüz bu tür duygularını düzenleyemiyor olmak, küçük çocukların büyük çocuklardan farklı olarak kaynak dağıtımında kendi lehlerine davranmaları ve eşitsizlikten kaçınmamaları sonucunu doğurabilir. Yaşla birlikte çocuklar sosyal karşılaştırma süreçlerinden daha az etkilenir hale gelir ve 7-8 yaşlarından itibaren kaynak dağıtımlarında eşitliği tercih ederler (Sheskin, Bloom ve Wynn, 2014).

Bazı araştırmalar ise, okul öncesi çocuklarda eşitsizlikten kaçınmaya dair yukarıda bahsedilen araştırmalardan farklı bulgular sunmakta ve farklı açıklamalar getirmektedir. Örneğin, ortak hareket edilerek (collaboration) tamamlanan bir iş sonucu elde edilen ödülün dağıtımı araştırmacı tarafından avantajlı eşitsizlik yaratacak şekilde düzenlenirse, 3 yaş çocuklarının dahi eşitsizlikten kaçındıkları, kendilerinde olan fazla kaynağı partnerine vererek kendini ve partnerini eş duruma getirdikleri bulunmuştur (Warneken, Lohse, Melis ve Tomasello, 2011). İki ve üç yaş çocukları ve şempanzeler ile yapılan çalışmada (Hamann, Warneken, Greenberg ve Tomasello, 2011), ortak iş yapılan (collaborative-birlikte iş yapılan) ve yapılmayan (windfall -iş yapılmayan- ya da parallel work- ayrı ayrı iş yapılan) koşullar oluşturulmuş ve 3 yaş civarında çocukların, ortak iş yapılan koşulda yapılmayan koşullara göre daha çok eşit dağıtımda bulundukları görülmüştür. Şempanzelerin kaynak paylaşımlarında ise ortak iş yapılan ve yapılmayan koşullar arasında bir farklılık bulunmamıştır. Benzer bir sonuca Melis, Hare ve Tomasello'nun (2006) şempanzelerle yaptıkları araştırmada da ulaşılmış, iki şempanzenin ortak iş yaparak ulaştığ 1 bir ödül şempanzelerden birine verildiğinde bu ödülü partneri ile paylaşmadığı bulunmuştur. Türler arası karşılaştırmalı çalışmaların bulguları, insan türüne özgü görünen kaynakları eşit dağıtma davranışının küçük yaşlarda ortak iş yaptıktan sonra görüldüğüne işaret etmektedir. Tomasello, Melis, Tennie, Wyman ve Herrmann (2012), evrimsel bir bakış açısıyla öne sürdükleri Dayanışma Modelinde (Interdependence Hypothesis) insana özgü birtakım bilişsel becerilerin ve yardımlaşma, 
eşit paylaşma gibi davranışların insanların iş birliği içerisinde ortak iş yaptığ süreçler ile oluştuğunu belirtmektedirler. Dayanışma modelinde, insan ontogenisinde erken yaşlarda görülen eşitlikten kaçınma davranışlarının ilk insan türlerinin bir kaynağa birlikte eriştikten sonra o kaynağı erişenler arasında eşit dağıtması ile bağlantılı olduğu belirtilmektedir (Tomasello ve Vaish, 2013). Ortak iş yapma yoluyla elde edilen kaynağı eşit dağıtmak, insanlar arasındaki işbirliğini devam ettiren bir yapı olma özelliğindedir.

Okul öncesi çocukların diğerine göre dezavantajlı eşitsizlikten kaçındığı halde avantajlı eşitsizlikten kaçınmadığ 1 hatta talep ettiği şeklindeki bulgular yaşa bağlı sosyal karşılaştırma süreçlerinin etkileri ile ilgili değil araştırmalarda çocuklara karşısında kimsenin olmadığ1 (örn., Fehr, Bernhard ve Rockenbach, 2008; Moore, 2009; Sheskin, Bloom ve Wynn, 2014), herhangi bir iş yapılmadan elde edilen kaynakların (windfall resources) çocukların önüne sunulduğu (Blake, Mcauliffe ve Warneken, 2014), önceden tanımlanmış dağıtım seçenekleri içeren seçime zorlama gibi paradigmaların kullanıldığı koşulların oluşturulmasından kaynaklanabilir (Warneken ve ark., 2011). Dezavantajlı eşitsizlikten kaçınma davranış1, şempanzelerde de görülebilen (Brosnan ve De Waal, 2003), küçük yaş çocuklarında da ortak iş yapmayı gerektirmeyen, avantajlı eşitsizlikten kaçınmaya göre evrimsel olarak daha ilkel/eski ve daha az sosyal bir yapı olabilir (McAuliffe ve ark., 2013). Avantajlı eşitsizlikten kaçınma ise daha sosyal ve kompleks bir yapı olabilir ve dayanışma modelinde belirtilen ortak iş yapmayı gerektiren sürece dahil olabilir. Ortak iş yapma, dezavantajlı eşitsizlikten kaçınmaya anlamlı bir etkide bulunmazken, avantajlı eşitsizlikten kaçınmaya anlamlı bir etkide bulunuyor olabilir. Ortak iş yapan küçük çocuklar yapmayanlara göre avantajlı eşitsizlik durumunda daha fazla eşitliği tercih ediyor olabilir.

$\mathrm{Bu}$ çerçevede mevcut araştırmanın amacı, okul öncesi çocuklarda ortak iş yapmanın (tam ortaklık, yarı ortaklık, kontrol gruplarında), eşitsizlik türünün (dezavantajlı ve avantajlı) ve bedellilik koşulunun (bedelli -eşitsizlikten kaçınma için kaynak feragatı gerektiren dağıtım- ve bedelsiz -eşitsizlikten kaçınma için kaynak feragatı gerektirmeyen dağıtım-) eşitsizlikten kaçınma davranışına etkide bulunup bulunmadığını incelemektir. Hamann ve arkadaşlarının (2011) araştırmasında tam ortaklık (collaborative work) ile yarı ortaklık koşulları (parallel work) arasında fark bulunması sebebiyle mevcut araştırmada da tam ve yarı ortaklık arasında bir fark çıkıp çıkmayacağı incelenmek istenmiştir. Eşitsizlik türü için, dezavantajlı eşitsizlik türünde avantajlıya göre anlamlı olarak daha fazla eşitsizlikten kaçınılması beklenmektedir. Bedellilik koşulu için, eşit- 
sizlikten kaçınmada bedelli ve bedelsiz dağıtım seçenekleri arasında anlamlı bir farklılik beklenmemektedir.

Bu araştırmada, Warneken ve arkadaşlarının (2011), belirttiğinin aksine seçime zorlama paradigmasının bu yaş çocukları için eşitliği tercih etmeyi zorlaştırdığı düşünülmemektedir. İlgili araştırmacıların belirttiği gibi çocukların ortak bir kaynak için birlikte çalışması eşitliği tercih etmeyi kolaylaştıran bir değişkense, bu durum seçime zorlama paradigması için de geçerli olabilir. Bilindiği kadarıyla, çocuklarda ortak iş yapmanın seçime zorlama paradigması ile eşitsizlikten kaçınma davranışına etkisini inceleyen araştırma bulunmamaktadır. Dolayısıyla mevcut araştırmanın, bu yaş çocuklarında görülen eşitsizlikten kaçınma ile ilgili bulguların yaştan dolayı duygu düzenlememe, ortak iş yapma ya da ölçüm için kullanılan paradigma (seçime zorlama paradigmasında önceden tanımlanmış seçeneklerin olması) gibi nedenlerinin belirlenmesinde katkı sağlayacağ 1 düşünülmektedir.

\section{YÖNTEM}

\section{Katılımcılar ve Araştırma Deseni}

Araştırmadaki katılımcılar, İstanbul'daki bir devlet üniversitesine bağlı kreşlerde eğitim gören, yaşları 50-72 ay arasında olan 80 (39 erkek, 41 kı) çocuktan oluşmaktadır. Katılımcılar seçilirken, Ankara Gelişim Tarama Envanteri’nden (AGTE) genel gelişim düzeyinin üstünde puan alması koşulları aranmıştır. Alıcı dil düzeyi ile çalışma belleğinin araştırmadaki değişkenleri etkileyebileceği göz önünde bulundurulmuş ve bunlara ait uç değerler (gelişimsel düzey olarak yaşıtlarından çok düşük ya da yüksek olan skorlar; örn., Peabody Resim ve Kelime Testinde 0-30 arasinda puan alan ya da Bay Patates Testinde 5 ve üzeri puan alan gibi) alan katılımcılar çıkartılarak deney grupları ile kontrol grubunun birbirleriyle denk olması sağlanmıştır. Deneysel koşullara seçkisiz olarak atanan katılımcılarda yaş, alıcı dil (Peabody Resim ve Kelime Testi-PRKT) ve çalışma belleği (Bay Patates Testi-BPT) skorları Tablo 1'de sunulmuştur.

Tablo 1. Deney Gruplarına Göre Takvim Yaşı, PRKT ve BPT Ortalama ve Standart Sapma Değerleri

\begin{tabular}{lllllll}
\hline & \multicolumn{2}{c}{ Takvim Yaşı (Ay) } & \multicolumn{2}{c}{ PRKT } & \multicolumn{2}{c}{ BPT } \\
\cline { 2 - 7 } & Ort. & SS & Ort. & SS & Ort. & SS \\
\hline Deney 1 $(N=27)$ & 61.07 & 6.60 & 60.15 & 8.93 & 2.25 & 0.48 \\
Deney 2 $(N=27)$ & 63.04 & 5.66 & 62.15 & 8.09 & 2.21 & 0.54 \\
Kontrol $(N=26)$ & 63.04 & 5.64 & 60.62 & 9.86 & 2.30 & 0.51 \\
\hline
\end{tabular}


Yaş, alıcı dil ve çalışma belleği açısından gruplar arasında farklar olup olmadığı çok değişkenli varyans analizi (MANOVA) ile test edilmiştir. Varyans analizi sonucunda, gruplar arasında, takvim yaşı ortalamaları $(F(2,77)=1.10, p>.05)$ PRKT ortalamaları $(F(2,77)=0.36, p>.05)$ ve BPT ortalamaları $(F(2,77)=0.18, p>.05)$ açısından anlamlı bir farklılık olmadığı görülmüştür.

Katılımcı çocukların demografik bilgilerine bakıldığında, 80 katılımcı çocuğun yaşları 50-72 ay arası iken yaş ortalaması 62 aydır $(S S=5.99)$. Katılımcıların \%97.5'i orta ekonomik seviyede, annelerinin \%82.5'i ve babalarının \%70'i üniversite mezunudur. Katılımcıların \%60’1 kardeşe sahip iken \%40’1 tek çocuktur. Sosyoekonomik düzey ve kardeş sayısı bakımından deney ve kontrol gruplarının benzer olduğu görülmüştür.

Deney ve kontrol grupları oluşturulurken, her grupta 27'şer katılımcı olacak şekilde gruplara seçkisiz atama yapılmıştır. Kontrol grubundaki 1 çocuk, uygulama esnasında yönergeyi anlamadığı için bu grubun sayısı 26'ya düşmüş, veriler toplamda 80 çocuk üzerinden değerlendirilmiştir. Deney grupları deney 1 ve deney 2 grubu olarak isimlendirilmiştir. Deney 1 grubunda yarı ortaklık, deney 2 grubunda ise tam ortaklık söz konusudur. Kontrol koşulunda çocuk tek başına iş yapmaktadır, ortaklık bulunmamaktadır.

Araştırma desenine bakıldığında, araştırma deneysel olup, üç tür manipülasyonu bulunmaktadır. Araştırmadaki üç bağımsız değişken; ortaklık koşulu (tam ortaklık, yarı ortaklık, kontrol), eşitsizlik türü (avantajlı eşitsizlik ve dezavantajlı eşitsizlik) ve bedellilik türü (bedelli ve bedelsiz) şeklinde iken, bağımlı değişken ise eşitsizlikten kaçınma davranışı yani eşitliği tercih etme şeklindedir. Araştırmanın bağımsız değişkenlerinden biri olan ortak iş yapma, boncuk ve kutu oyunu (işlem kısmında bahsedilmektedir) yoluyla oluşturulmuştur. Deneysel koşullar hakkındaki özet bir bilgi Tablo 2'de gösterilmektedir.

Tablo 2. Araştırmadaki Deneysel Koşullar

\begin{tabular}{ccc}
\hline $\begin{array}{c}\text { Deney } \mathbf{1} \text { grubu } \\
(\mathbf{N}=\mathbf{2 7})\end{array}$ & $\begin{array}{c}\text { Deney } \mathbf{2} \text { grubu } \\
(\mathbf{N}=\mathbf{2 7})\end{array}$ & $\begin{array}{c}\text { Kontrol grubu } \\
(\mathbf{N}=\mathbf{2 6})\end{array}$ \\
\hline Partner ile Yarı Ortaklık & Partner ile Tam Ortaklık & Partner ile Ortaklık Yok \\
+ & + & + \\
Eşitsizlikten Kaçınma & Eşitsizlikten Kaçınma & Eşitsizlikten Kaçınma \\
\hline
\end{tabular}

\section{Veri Toplama Araçları}

Demografik Bilgi Formu. Bu form, çocuğun yaşı, cinsiyeti, kardeş sayısı, ekonomik seviye ve anne-baba eğitim durumu gibi çocuk hakkındaki bilgilere ulaşmak ama- 
cıyla araştırmacı tarafından hazırlanmış ve kreş yönetimi ile öğretmenlerin yardımıyla doldurulmuştur.

Ankara Gelişim Tarama Envanteri (AGTE). Araştırmanın kontrol değişkenlerinden biri olan katılımcıların genel gelişim düzeylerini belirlemek amacıyla kullanılmıştır. AGTE, 0-6 yaş arası çocukların, dil-bilişsel, ince motor, kaba motor ve sosyal beceri-öz bakım alanlarında gelişimsel düzeyini değerlendirmek amacıyla Savaşır, Sezgin ve Erol tarafından 1992 yılında geliştirilmiştir. Envanter toplamda 154 maddeden ve dil-bilişsel, ince motor, kaba motor ve sosyal beceri-öz bakım olmak üzere 4 alt testten oluşmaktadır. Dil-Bilişsel Gelişim alt testi (D.B.) 65 maddeden oluşmakta ve basit ses ve sözel davranışlar ile karmaşık dil ifadeleri, dili anlama ve açık olarak ifade edebilme, basit problem çözme, sayı-zaman kavramı gibi becerileri kapsamaktadır. İnce Motor (İ.M.) beceriler alt testi 26 maddeden oluşup basit el-göz koordinasyonundan karmaşık ince motor davranışlara dayanan görsel-motor becerileri; Kaba Motor (K.M.) beceriler alt testi ise 24 maddeden oluşup harekete dayanan kuvvet, denge ve koordinasyonu ölçmektedir. Sosyal Beceri-Öz Bakım (SB-ÖB) alt testi ise 39 maddeden oluşmakta ve yeme, giyinme gibi öz bakım alışkanlıkları ile özerklik, sosyal etkileşim gibi özelliklerin ölçümünü içermektedir. Dil-Bilişsel, İnce Motor, Kaba Motor ve Sosyal Beceri- Öz Bakım puanları ve bütün bu alt testlerin toplamından oluşan genel gelişim puanı olmak üzere 5 ayrı puan elde edilmektedir. Alınabilecek en yüksek puan 154, en düşük puan 0 'dır. Bu puanlar, $t$-tablosundaki skorlara çevrilmekte ve $t$ skoru 40-60 arası olan çocukların gelişim düzeylerinin yaş dönemine uygun olduğu kabul edilmektedir. Çalışmada, Savaşır, Sezgin ve Erol'un (2006) düzeltilmiş 4. baskısı kullanılmıştır.

Peabody Resim Kelime Testi (PRKT). Araştırmanın bir diğer kontrol değişkeni olan katılımcıların alıcı dil düzeyini belirlemek amacıyla kullanılmıştır. Test, 2-12 yaş arası çocukların alıcı dil yetilerine yönelik kelime bilgilerinin gelişimini ölçmek için Dunn (1965) tarafından geliştirilmiş; Katz, Demir, Önen, Uzlukaya ve Uludağ (1972), tarafından Türkçe'ye uyarlanmıştır. Testin materyali, her birinde dört ayrı resmin bulunduğu 100 adet resimli karttır. Bu kartlar, sırasıyla katılımcının önüne konur ve her bir karttaki resimlerden birinin adı söylenir. Katılımcıdan adı söylenen resmi işaret etmesi istenmektedir. Katılımcıya gösterilen son sekiz kartın altısında yanlış resmin işaret edilmesi üzerine uygulama sonlandırılır. Gösterilen son kartın sıra numarasından, uygulama boyunca yanlış resmin işaret edildiği kart sayısı kadar çıkartılarak, katılımcının "alıcı dil ham puanı" elde edilir. Orijinal testin paralel form güvenirliği .64 ile .84 olarak bildi- 
rilmiştir. Ölçüt bağımlı geçerliğinin hesaplanmasında ise, Stanford-Binet Zeka Testi ile .82-.86; WISC-R ile de .41-.74 arasında değişen ilişkiler bulunmuştur (Öner, 2006).

Bay Patates Testi (BPT). Araştırmanın bir diğer kontrol değişkeni olan katılımcıların kısa süreli bellek düzeyleri, Case (1985) tarafından geliştirilen De Ribaupierre ve Bailleux (1994) tarafından revize edilen Bay Patates Testi ile ölçülmüştür. Çocuklara bir patates adam resmi ardından vücudunun farklı yerlerinde renkli ponponların olduğu bir ponponlu patates adam resmi gösterilir. Bu resim kaldırılarak, çocuğa ponponu olmayan patates adam resmi gösterilerek diğer resimdeki ponponların yerini göstermesi istenir. Eğer çocuk denemelerde başarılı olursa asıl uygulamaya geçilmektedir. Asıl uygulamada üzerindeki ponpon sayısına göre 1'den 8'e kadar sıralı biçimde seviyesi artarak devam eden Bay Patates resimleri (Şekil 1'de gösterilmektedir) bulunmaktadır. Her seviyede 3 adet resim, toplamda 24 adet ponponlu resim bulunmaktadır. Her bir resmin sunum süresi, üzerindeki ponpon sayısına göre, ponpon başına $1 \mathrm{sn}$. olarak belirlenir. Çocuğa doğru gösterilen her resim için $(+)$ doğru gösterilmeyen her resim için $(-)$ verilmektedir. Ĕger aynı seviyedeki 3 resmin de ponponlarını doğru gösteremez ve bu seviyedeki 3 resimden de (-) alırsa uygulama bitirilir. Puanlama yapılırken, çocuğun aynı seviyedeki 3 resimden en az 2'sini doğru cevaplamasıla bu seviyeyi geçtiği kabul edilmekte ve 1 puan verilmekte, bu kriteri sağladığı ardışık seviyelerden sonra ise her doğru cevap (+) için 1/3 puan verilmektedir. Bu test için alınabilecek puan aralığı 0 ile 8 arasındadır.
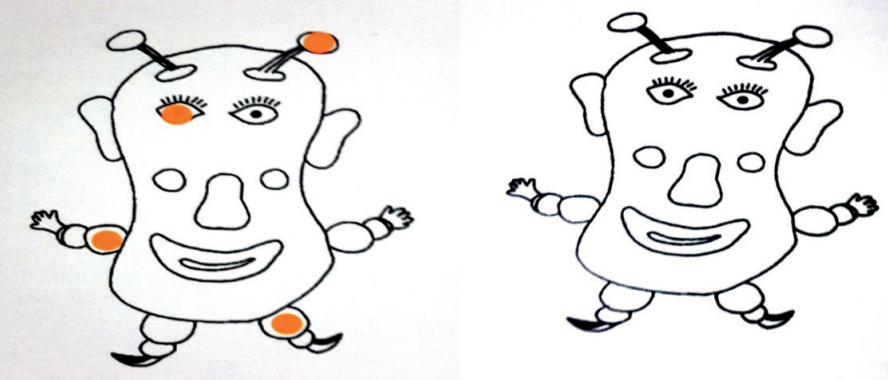

Şekil 1. Bay Patates Testi (BPT) Resimleri

Seçime Zorlama Oyunu (Forced Choice Game). Bu oyun, araştırmadaki bağımlı değişken olan eşitsizlikten kaçınmayı belirleme amaçlı kullanılmıştır. Ayrıca eşitsizlik türü ve bedellilik koşulu bağımsız değişkenleri, bu oyunda oluşturulan kaynak dağıtım koşulları vasıtasıyla incelenmiştir. Oyunda klasik olarak, katılımcılara, eşitliğin (eşit 
paylı dağıtım koşulu) ve dezavantajlı (katılımcı için diğerine göre daha az pay) ya da avantajlı eşitsizliğin (katılımcı için diğerine göre daha çok pay) olduğu iki koşul birlikte sunularak bir tanesini tercih etmesi istenmektedir. Katılımcı eğer eşit koşulu seçerse, kendisi ve diğerine aynı miktarda pay düşmektedir. Eşitsizlik durumunda ise kendi payı diğerine göre daha az olursa dezavantajli; kendi payı diğerine göre daha fazla olursa avantajlı eşitsizliği tercih etmiş olmaktadır.

Thompson, Barresi ve Moore (1997), herhangi bir materyal ya da aparat kullanılmaksızın sözel bildirim yoluyla çocukları seçime zorlamıştır. Orijinali "şimdi sana 1, ertelersen sana 2 tane" şeklinde olan haz erteleme paradigmasını, "şimdi sana 1, ertelersen 1 sana 1 ona" şeklinde diğer çocuğu da içeren iki seçenekli olacak şekilde düzenlemişlerdir. Bu oyunu aparat içerecek şekilde Silk ve arkadaşları (2005), (1/1-1/0) şeklinde düzenleyerek şempanzelerle oynamışlardır. Oyun, birinin alıcı diğerinin karar verici olduğu iki şempanzenin karşı karşıya geleceği ve aralarında bir aparatın olacağı şekilde tasarlanmıştır. Aparattaki ödüller karar verici şempanzenin görebileceği ve iplerin sadece bir tanesini çekebileceği biçimde düzenlenmiştir. Bu iplerden bir tanesinin çekilmesiyle her iki şempanze de aynı sayıda ödül alırken, diğerinin çekilmesiyle bir şempanze diğerine göre az ya da fazla almaktadır. Fehr, Bernhard ve Rockenbach (2008), ise çocuklara dikdörtgen şeklinde iki ucunda çizilmiş farklı sayıda daire şekillerinin olduğu iki ayrı kartı, daireler hangi taraf için çizilmişse çocuklar o uçta olacak şekilde sunmuştur. Çocuklardan bu iki karttan bir tanesini seçmeleri istenmiş ve oyun sonunda seçtikleri karttaki çizilen daire sayısı kadar iki tarafın da ödül alacağı belirtilmiştir.

Mevcut araştırmadaki oyun için kullanılacak materyal, Sheskin, Bloom ve Wynn'ın (2014), kullandıkları düzenek örnek alınarak oluşturulmuştur. Materyal, 36x36 cm ebadında kartondan yapılmış bir zemin ile dağıtım paylarını belirleyen taşlardan oluşmaktadır. Karton zemin bir tarafı mavi, diğeri yeşil olmak üzere dikey olarak ikiye bölünmüş ve iki ayrı renkte $15 \times 30 \mathrm{~cm}$ 'lik iki dikdörtgen oluşmuştur. Daha sonra bu dikdörtgenler de yatay olarak ikiye bölünmüş ve $15 \times 15$ cm'lik iki adet mavi, 15x15 cm'lik iki adet yeşil olmak üzere dört kare oluşmuştur. Bu karelerin her biri, kalemle çizilerek dama tahtası gibi $2 \times 2 \mathrm{~cm}$ 'lik karelere ayrılmıştır. Karelerin birbirine ve köşelere olan uzaklıkları eşittir. Kaynak dağıtımındaki payları göstermek için küçük taşlar kullanılmış ve bunlar küçük karelerin ortasına yerleştirilmiştir. İki farklı renkteki büyük karelerden bir renkte eşit dağıtım koşulu, diğer renkte ise eşitsizliğin olduğu dağıtım koşulu yer almaktadır. Çocuk ile partneri Bibo'nun karşılıklı oturduğu bir durumda, ço- 
cuğun önüne iki farklı dağıtım için kendi alacağı kadar taş, partnerinin önüne ise iki farklı dağıtım için onun alacağı kadar taş konulmaktadır. Çocuğa mavi ya da yeşil taraftan birini seçebileceği; seçtiği taraftaki taşların sayısına göre her ikisinin ödül alacağı söylenmektedir. Hangi rengi seçerse, o renkte bulunan kendisinin ve diğerinin önündeki taşlar, siyah bir kartonun içine atılmakta, seçmediği renkteki taşlar ise taşların olduğu kutuya geri konmaktadir.

$\mathrm{Bu}$ araştırmada, ödül olarak çıkartma verilmiş ve dağıtımlardaki kaynak sayıları Sheskin, Bloom ve Wynn (2014) araştırmasındaki ile aynı şekilde kullanılmıştır. Buna göre, bir bedelsiz dezavantajlı, bir bedelli dezavantajl1, bir bedelsiz avantajlı, bir bedelli avantajlı eşitsizliğin olduğu koşulları içeren 2x2'lik 4 adet dağıtım koşulu bulunmaktadır. Dağıtımlar, çocuğa bir kez sunulmuş ve sunuluş sıralarının çocukların tercihlerine etkisi olabileceği düşünüldüğünden her grupta sunum sıraları karşıt dengeleme ile verilmiştir. Ayrıca, uzamsal seçimin de tercihleri etkileyebileceği düşünüldügünden eşit ve eşit olmayan koşulun olduğu renkler, her katılımcıda dağıtımlar arasında dengelenmiştir. Dağıtım koşulları Tablo 3’te gösterilmektedir.

Tablo 3. Araştırmadaki Dağıtım Koşulları

\begin{tabular}{|c|c|c|c|c|}
\hline \multirow[b]{2}{*}{ Dezavantajlı Eşitsizlik } & \multicolumn{2}{|c|}{ Bedelsiz Dağıtım } & \multicolumn{2}{|c|}{ Bedelli Dağıtım } \\
\hline & Mavi & Yeşil & Mavi & Yeşil \\
\hline & $2 *$ & 2 & 2 & 1 \\
\hline & $2 * *$ & 3 & 3 & 1 \\
\hline \multirow[t]{3}{*}{ Avantajlı Eşitsizlik } & Mavi & Yeşil & Mavi & Yeşil \\
\hline & $2 *$ & 2 & 1 & 2 \\
\hline & $2 * *$ & 1 & 0 & 2 \\
\hline
\end{tabular}

*Çocuğun kendi tarafındaki sonucu, $* *$ ise diğerinin tarafındaki sonucu göstermektedir.

Bedelsiz dağıtım, çocuğun mavi ya da yeşil tercihinde aldığı kaynağın sabit olmasını ifade etmektedir

Bedelli dağıtım, çocuğun mavi ya da yeșil tercihinde aldığı kaynağın azalmasını ya da artmasını ifade etmektedir.

Oyunun puanlanmasında, çocuğa seçtiği rengin eşit dağıtım koşulu olduğu her seçimden 1 puan, seçilen rengin eşitsizlik koşulu olduğu her seçimden ise 0 puan verilmektedir. Toplamda alınabilecek puan 0 ile 4 arasındadır.

\section{İşlem}

Uygulamalar, katılımcıların devam ettiği ana okulunda bulunan sessiz bir odada 2 oturum halinde ve bireysel olarak yürütülmüştür. Odada, dikdörtgen bir masa ve araştırmacı ile çocuğun masada karşılıklı oturabileceği iki sandalye ve araştırmacının yanında materyallerini koyabileceği bir sandalye daha bulunmaktadır. 
İlk oturumda PRKT ve BPT uygulanmıştır. Uygulamalara başlamadan önce, tanışma ve ısınma amacıyla çocukların sınıflarında bir süre zaman geçirilmiştir. Birinci oturum yaklaş1k olarak 15-20 dakika sürmüştür.

Bir hafta sonra deneysel müdahaleyi (tam ve yarı ortaklık koşulları) içeren ikinci oturum gerçekleştirilmiştir. Araştırmanın bağımsız değişkenlerinden biri olan ortaklığ sağlamak için, katılımcı ile renkli boncukların sınıflanarak toplanmasını gerektiren bir işte iş birliği yapan "Bibo" isimli bir el kuklası kullanılmıştır.

Yarı ortaklık (Deney 1) koşulunda, masanın üzerinde içinde 5 tane mavi boncuğun bulunduğu mavi kutu ve 5 tane yeşil boncuğun bulunduğu yeşil kutu, yanına da 5 tane mavi ve 5 tane yeşil boncuk karışık halde konulur. Oyunda bu boncukları rengine göre kutulara koymak gerektiği belirtilir ve Bibo çıkartılarak Bibo’nun bu oyuna başladığı ancak yarım bıraktığı, kendisinin tamamlamak isteyip istemediği sorulur. Çocuk, boncukları yerleştirdiğinde Bibo’ya yarısını yaptığı için 5 tane, kendisine de diğer yarısını tamamladığ çocuğa bu oyunu da Bibo ile birlikte oynayacağı belirtilir. Her dağıtım koşulu için taşlar karelerin önüne konularak çocuğa hangi rengi seçtiği sorulur. Oyun bittiğinde çocuğun önünde biriken taş sayısı kadar kendisine, Bibo’nun önünde birikenler kadar Bibo’ya çıkartma verilerek uygulama bitirilir.

Tam Ortaklık (Deney 2) koşulunda çocuğun önüne mavi kutu ve yeşil kutu, yanına da 10 tane mavi ve 10 tane yeşil boncuk karışık halde konulur. Oyunda bu boncukları rengine göre kutulara koymak gerektiği belirtilir ve Bibo çocuktan bu işi birlikte yapmalarını ister. Bibo ilk boncuğu rengine göre kutusuna koyarak oyuna başlar ve çocuğun devam etmesini bekler. Bütün boncuklar sırayla ve eşit miktarda kutusuna koyulduktan sonra araştırmacı kendi sesiyle konuşarak ikisine de 5'er tane çıkartma verir. Daha sonra seçime zorlama oyununa geçilerek bu oyunu da Bibo ile birlikte oynayacağ belirtilir. Her dağıtım koşulu için taşlar karelerin önüne konularak çocuğa hangi rengi seçtiği sorulur. Oyun bittiğinde çocuğun önünde biriken taş sayısı kadar kendisine, Bibo’nun önünde birikenler kadar Bibo'ya çıkartma verilerek uygulama bitirilir.

Kontrol grubunda ise çocuktan boncuk tasnifleme işini tek başına yapması istenir ve 5 tane çıkartma verilir. Daha sonra seçime zorlama oyununa geçilerek, Bibo çıkartılır ve bu oyunu Bibo ile birlikte oynayacağı belirtilir. Her dağıtım koşulu için taşlar karelerin önüne konularak çocuğa hangi rengi seçtiği sorulur. Oyun bittiğinde çocuğun önünde 
biriken taş sayısı kadar kendisine, Bibo'nun önünde birikenler kadar Bibo’ya çıkartma verilerek uygulama bitirilir. Uygulamalar yaklaşık 15 dakika sürmüştür.

\section{BULGULAR}

Dört dağıtım koşulunda eşitsizlikten kaçınmanın (eşitliği tercih etme) ortaklık koşuluna göre oluşturulan gruplarda ayrı ayrı ve toplam katılımcılarda betimsel istatistik değerleri Tablo 4'te gösterilmektedir.

Tablo 4. Dört Dağıtım Koşulunda Eşitsizlikten Kaçınmada Tüm Katılımcılar ve Gruplara Göre Ortalama, Standart Sapma ve Yüzdelik Değerleri

\begin{tabular}{|c|c|c|c|c|c|c|c|c|c|c|c|c|}
\hline & $\begin{array}{c}\text { Dezav } \\
\text { Eşitsiz }\end{array}$ & $\begin{array}{l}\text { ntajlı } \\
\text { kten }\end{array}$ & $\begin{array}{l}\text { Bedelli } \\
\text { açınma }\end{array}$ & $\begin{array}{l}\text { Dezav } \\
\text { Eşitsiz }\end{array}$ & $\begin{array}{l}\text { atajlı } \\
\text { kten I }\end{array}$ & $\begin{array}{l}\text { edelsiz } \\
\text { açınma }\end{array}$ & $\begin{array}{r}\text { Avan } \\
\text { Eşitsizl }\end{array}$ & $\begin{array}{l}\text { tajlı B } \\
\text { kten } \mathbf{F}\end{array}$ & $\begin{array}{l}\text { delli } \\
\text { açınma }\end{array}$ & $\begin{array}{r}\text { Avan } \\
\text { Eşitsizl }\end{array}$ & $\begin{array}{l}\text { ajlı B } \\
\text { kten I }\end{array}$ & $\begin{array}{l}\text { lelsiz } \\
\text { Içınma }\end{array}$ \\
\hline & Ort. & $S S$ & $\%$ & Ort. & $S S$ & $\%$ & Ort. & $S S$ & $\%$ & Ort. & $S S$ & $\%$ \\
\hline $\begin{array}{l}\text { Deney } 1 \\
(N=27)\end{array}$ & 0.30 & 0.46 & 29.6 & 0.70 & 0.46 & 70.4 & 0.48 & 0.50 & 48.1 & 0.67 & 0.48 & 66.7 \\
\hline $\begin{array}{l}\text { Deney } 2 \\
(N=27)\end{array}$ & 0.30 & 0.46 & 29.6 & 0.52 & 0.50 & 51.9 & 0.59 & 0.50 & 59.3 & 0.63 & 0.49 & 63 \\
\hline $\begin{array}{l}\text { Kontrol } \\
(N=26)\end{array}$ & 0.42 & 0.50 & 42.3 & 0.46 & 0.50 & 46.2 & 0.50 & 0.51 & 50 & 0.58 & 0.50 & 57.7 \\
\hline $\begin{array}{l}\text { Katılımcilar } \\
(N=80)\end{array}$ & 0.34 & 0.47 & 33.8 & 0.56 & 0.49 & 56.2 & 0.52 & 0.50 & 52.5 & 0.62 & 0.48 & 62.5 \\
\hline
\end{tabular}

Çıkarımsal istatistikte, üç bağımsız değişkeni içeren -ortaklık koşulu (tam ortaklık, yarı ortaklık, kontrol) -eşitsizlik türü (dezavantajlı, avantajlı) -bedellilik koşulu (bedelsiz, bedelli) 3x2x2 karışık model tekrarlı ölçümler için ANOVA uygulanmıştır. Eşitsizlik türü ve bedellilik koşulu değişkenleri grup içi faktör, ortaklık koşulu gruplar arası faktör, eşitsizlikten kaçınma ise bağımlı değişken olarak değerlendirilmiştir.

Bulgulara bakıldığında, gruplar arası faktör olan ortaklık koşulunun temel bir etkisinin olmadığ 1 görülmüştür $\left(F(2,77)=0.25, p=0.78, \eta_{\mathrm{p}}{ }^{2}=.01\right)$. Grup içi faktörlerden biri olan eşitsizlik türünün temel bir etkisinin olduğu $\left(F(1,77)=6.18, p=0.02, \eta_{\mathrm{p}}{ }^{2}=.07\right)$ katılımcıların avantajlı eşitsizlik türünde $($ Ort. $=1.15, S S=0.64)$ dezavantajlı eşitsizlik türüne (Ort. $=0.90, S S=0.67)$ göre eşitliği daha fazla tercih ettikleri görülmüştür. Grup içi faktörlerden biri olan bedellilik koşulunun temel bir etkisinin olduğu $(F(1,77)=$ $\left.7.25, p=0.01, \eta_{\mathrm{p}}{ }^{2}=.09\right)$ katılımcıların bedelsiz dağıtım türünde $($ Ort. $=1.19, S S=0.71)$ bedelli dağıtım türüne (Ort. $=0.86, S S=0.73$ ) göre eşitliği daha fazla tercih ettikleri görülmüştür. Bağımsız değişkenler arasında ikili ya da üçlü düzeyde herhangi bir etkileşim etkisine rastlanmamıştır. 


\section{TARTIŞMA}

Ortak iş yapmanın kaynak dağıtımında eşitsizlikten kaçınma üzerindeki etkisini inceleme amaçlı bu araştırmanın sonuçlarına göre, ortak iş yapmanın eşitsizlikten kaçınma yani eşitliği tercih etme üzerinde anlamlı bir etkisi bulunmamıştır. Eşitsizlik türünün ve bedellilik koşulunun eşitliği tercih etme üzerinde anlamlı etkileri olduğu bulunmuştur. Eşitsizlik türünün etkisine bakıldığında, avantajlı türde eşitliği tercih etmenin dezavantajlı türe göre daha fazla olduğu; bedellilik koşulunun etkisine bakıldığında ise bedelsiz dağıtımda eşitliği tercih etmenin bedelli dağıtıma göre daha fazla olduğu görülmüştür.

Mevcut çalışma, dayanışma modelinde belirtilen bu yaş çocuklarının eşitliği tercih etmesi için ortak iş yapmaları gerektiği görüşü ve ortak iş yapanların yapmayanlara göre avantajlı eşitsizlikten daha çok kaçındığı araştırma bulguları (Hamann ve ark., 2011; Warneken ve ark., 2011) ile tutarlı değildir. Mevcut araştırmanın sonuçlarına bakıldığında, ortak iş yapmanın avantajlı eşitsizlikten kaçınma için gerekli olmadığı ancak bunu artırıcı bir faktör olabileceği düşünülebilir. Nitekim, gruplar arasında fark olmamasına karşın en yüksek avantajlı eşitsizlikten kaçınma puanları tam ortaklığın olduğu deney 2'de görülmektedir (Bkz. Tablo 4). Eşitsizlikten kaçınma, işbirlikçi etkileşimlerde artabilir ancak nedeninin bu etkileşimler olup olmadığı tartışmalı görünmektedir.

Mevcut araştırmada çocukların avantajlı eşitsizlik türünde dezavantajlıya göre daha fazla eşitliği tercih etmeleri, sosyal karşılaştırma süreçlerinden etkilenip duygularını henüz düzenleyemedikleri için dezavantajlı olmak istemeyip avantajlı olmak istedikleri görüşü ile tutarlı değildir (Sheskin, Bloom ve Wynn, 2014). Ayrıca bu yaş çocuklarının dezavantajlı eşitsizlikten kaçınıp avantajlı eşitsizliği tercih ettiği birçok araştırma bulgusu (Blake ve Mcauliffe, 2011; Fehr, Bernhard ve Rockenbach, 2008) ile tutarlı değildir. Araştırmacılar, eşitsizlikten kaçınmanın “ben” yönelimli olarak tanımlanabilecek dezavantajlı türünün 4 yaşlarında ve "diğeri” yönelimli olarak tanımlanabilecek avantajlı türünün ise 8 yaşlarında görülmeye başladığını, bu bakımdan iki eşitsizlik türünün farklı gelişimsel çizgilere ve psikolojik süreçlere sahip olduğunu belirtmektedirler. Buna göre, gelişimsel olarak kendi yönelimli bir tercihten diğeri yönelimli bir tercihe geçiş yapılmaktadır, dezavantajlı türde 4 yaştan 8 yaşa bir artış olabilirken, avantajlı türde bu iki yaşta radikal bir değişim söz konusudur. Araştırmacıların belirttiği gibi iki farklı tür için farklı gelişimsel ve psikolojik süreçler söz konusu olabilir, ancak Piaget'nin (2002) bir 
evresinden diğerine geçiş mantığıyla dezavantajlı eşitsizlikten kaçınma evresinden avantajlı eşitsizlikten kaçınma evresine geçiş fikri tartışmalı görünmektedir. Dezavantajlı eşitsizlikten kaçınmanın ve avantajlıyı talep etmenin aşılması gereken bazı olumsuz duygular ile ilişkili olduğu ve ancak aşıldıktan sonra yani gelişimin daha geç bir evresinde ortaya çıkan avantajlı eşitsizlikten kaçınmanın ise diğeri yönelimli duygular (örn., alturistik duygular) ile ilişkili olduğu yaklaşımı yerine alternatif senaryolar göz önünde bulundurulup test edilmelidir.

Mevcut araştırmada, bedellilik durumunun yani eşitlik ve eşitsizlik arasında tercih yaparken kaynaklarından feragat edip etmeyeceklerinin çocukların tercihlerinde etkili olduğu bulunmuştur. Bu sonuç, yetişkinlerin eşitsizlik durumunu eşit hale getirebilmek için kaynaklarından feragat ettiklerini belirten eşitsizlikten kaçınma modeli (Fehr ve Schmidt, 1999) ile tutarlı bulunmamıştır. Bir varsayım, çocukların yetişkinlere göre kaynağın kendileri için daha fazla olduğu koşulu tercih ederek ekonomik davranmış olabilecekleri şeklindedir. Bununla ilgili diğer bir varsayım, yetişkinlerin araştırmalarda tercihlerini yaparken çocuklara göre itibarlarını daha çok gözetmeleri, dolayısıyla fazla kaynak almayı hatta eşitlik için kaynak feragatında bulunmamayı itibarsız bulmaları olabileceği şeklindedir. Benzer bir bulguya, 4-6 yaş çocuklarında dezavantajlı eşitsizlikten kaçınmayı inceleyen bir araştırmada da rastlanmıştır (Williams ve Moore, 2014). Dağıtım koşulları mevcut araştırmadan farklı olsa da bedel içeren koşullarda içermeyene göre eşitliği tercih etme daha fazla görülmüştür. Dahası araştırmada bedel içeren koşullarda, eşitsizliğin büyüklüğünün daha çok olduğu durumda daha az olduğu duruma göre (örn., 0/0-1/2 ve 0/0-1/5 gibi) eşitliği tercih etme daha fazla iken, bedelsiz koşullarda böyle bir farka rastlanmamıştır. Mevcut araştırmada eşitsizliğin derecesi gibi bir manipülasyon yapılmamıştır, ancak ileriki çalışmalarda her iki eşitsizlik türü için de denenip bakılabilir. Ayrıca, farklı dağıtımlar sonuçları farklılaştırabileceği için daha fazla olasılığı içeren koşullar, çocukların tercih nedenlerine ilişkin daha net yorumlar yapmay1 sağlayabilir. Örneğin, mevcut araştırmadaki avantajlı eşitsizlikten kaçınmayı inceleyen "1/0-2/2" dağıtımına ek olarak "1/1-3/2” gibi bir dağıtım (avantajlı eşitsizlikten kaçınmak için bedel ödemeyi yani kaynak feragatını gerektiren) ile çocukların tercihlerine bakılabilir. Bu şekilde bir dağıtım koşulu eklenerek, dağıtımda avantajlı olup olunmaması ya da kendi alacağının daha fazla olup olmamasının çocukların tercihlerine olan etkisi daha net görülebilir. Dahası eşitlik tercihleri belirtilenlerden farklı nedenlerle de görülebilir. Örneğin araştırmadaki “1/0-2/2” koşulunda kendisi için daha fazla kaynak 
olduğundan ya da avantajlı eşitsizlikten kaçınmak için değil, diğerinin “ 0 ” almasını yani hiçbir kaynak almamasını ortadan kaldırmak için eşitlik tercih edilmiş olabilir. İlerideki araştırmalar farklı dağıtım koşullarıyla bu ihtimalleri test edebilir, örneğin bedelsiz dağıtımlardaki çocuğun kendi kaynağının sabit tutulduğu koşullara ek olarak diğerinin kaynağının sabit tutulduğu "1/1-2/1" gibi bir dağıtım koşulu da çocukların tercih nedenlerine dair daha iyi bir cevap verebilir (Blake ve Mcauliffe, 2011).

Çalışmanın sınırlılıklarına bakıldığında, ortak iş yapılan kuklanın araştırmacının elinde olması ve katılımcı çocuklar ile karşı karşıya oynaması, bazı çocuklarda oyunu araştırmacı ile oynuyor hissi yaratmış ve sonuçları etkilemiş olabilir. Bir araştırmada, çocukların oyunlarda karşı taraf yetişkin bir araştırmacı olduğunda eşit seçeneği daha çok tercih ettikleri bulunmuştur (Thompson, Barresi ve Moore, 1997). Gelecek çalışmalar, daha büyük bir kukla kullanılarak (Kanngiesser ve Warneken, 2012) ve sadece bu kukla çocuğun karşısına oturtulup araştırmacı ikisine de aynı mesafede ve yanlarında duracak biçimde pozisyon alarak araştırma yapılabilir. Ya da kukla, görünmeyen bir panelin arkasından sunularak araştırmacının görünmemesi sağlanabilir. Ayrıca ilerideki çalışmalarda, eşitsizlikten kaçınmanın ebeveynlerin paylaşma ve eşitliğe dair tutumları-davranışları (örneğin büyük çocuğa, kardeşine daha fazla vermesini söyleme ya da ikisinin de eşit alması yönünde hareket etme) ile ilişkisine bakılabilir. Nitekim, eşitlik tercihleri ile ilgili farklı kültürlerde farklı bulgulara (Paulus, 2015; Schafer, Haun ve Tomasello, 2015) rastlanılabilmektedir. Bilindiği kadarıyla Türk kültüründe bu yaş çocuklarının eşitsizlikten kaçınma karşısındaki tercihlerini inceleyen araştırma bulunmamaktadır. Çocuklarda gelişimsel bir çizgide ilerleyen-yaşla birlikte artan genel bir eşitsizlikten kaçınma prensibinin olup olmadığını ve bireysel-kültürel farklılıkları test etmenin bir diğer yolu, boylamsal araştırma yapmaktan geçebilir. Çocuklar 4 yaşından itibaren farklı oyunlarla 7-8 yaşlarına gelene kadar test edildiğinde, yaşa bağlı bir değişim olup olmadığına bakılarak bu tartışmalara daha iyi bir zemin hazırlanabilir.

Sonuç olarak bu çalışmanın, okul öncesi çocuklarda ortak iş yapmanın eşitsizlikten kaçınma üzerinde etkisi olmadığını bulması ile literatürdeki dayanışma modeline ve çocukların avantajlı eşitsizlik durumunda dezavantajlıya göre daha fazla eşitsizlikten kaçınma gösterdiklerini bulması ile sosyal karşılaştırma süreçlerini vurgulayan görüşlere zıt bulgular sunması ile literatüre yeni problemler kattığı söylenebilir. Çalışmadaki birtakım sınırlılıklara rağmen, ortak iş yapmanın seçeneğe zorlama oyununda- 
ki eşitsizlikten kaçınma tercihlerine etkide bulunup bulunmadığını incelemesi bakımından çalışmanın öneme sahip olduğu düşünülmektedir. Ayrıca dağıtımların bedelli yapılıp yapılmamasının çocukların eşitliği tercihinde etkisi olduğu görülmüştür. $\mathrm{Bu}$ sonuçlara göre, çocukların diğeri ile arasında eşitsizlik yaratan durumları eşit hale getirmek için kaynaklarından feragat ettikleri şeklindeki eşitsizlikten kaçınmaya dair yaklaşımlarının daha kritik biçimde ele alınması gerektiği söylenebilir. Bu araştırma, okul öncesi çocuklarda eşitsizlikten kaçınmanın katı (gelişimsel çizgide önce dezavantajlı sonra avantajlı eşitsizlikten kaçınmanın görüldüğü ya da eşitsizlikten kaçınma için ortak iş yapmayı gerektiren) değil esnek bir davranış olabileceğini düşündürmektedir.

Finansal Destek: Yazarlar bu çalışma için finansal destek almamışlardır.

\section{Kaynakça}

Adams, J. S. (1965). Inequity in social exchange. L. Berkowitz (Ed.), Advances in experimental social psychology içinde (Cilt 2, s. 267-299). New York: Academic Press.

Blake, P. R. ve McAuliffe, K. (2011). "I had so much it didn't seem fair": Eight-year-olds reject two forms of inequity. Cognition, 120(2), 215-224.

Blake, P. R., McAuliffe, K. ve Warneken, F. (2014). The developmental origins of fairness: The knowledge-behavior gap. Trends in Cognitive Sciences, 18(11), 559-561.

Brosnan, S. F. ve De Waal, F. B. (2003). Monkeys reject unequal pay. Nature, 425(6955), 297-299.

Case, R. (1985). Intellectual development: Birth to adulthood. New York: Academic Press.

De Ribaupierre, A. ve Bailleux, C. (1994). Developmental change in a spatial task of attentional capacity: An essay toward an integration of two working memory models. International Journal of Behavioral Development, 17(1), 5-35.

Dunn, L. M. (1965). Expanded manual for the Peabody Picture Vocabulary Test. American Guidance Service.

Fehr, E., Bernhard, H. ve Rockenbach, B. (2008). Egalitarianism in young children. Nature, 454(7208), 1079-1083.

Fehr, E. ve Schmidt, K. M. (1999). A theory of fairness, competition, and cooperation. The Quarterly Journal of Economics, 114(3), 817-868.

Festinger, L. (1954). A theory of social comparison processes. Human Relations, 7(2) 117-140.

Hamann, K., Warneken, F., Greenberg, J. R. ve Tomasello, M. (2011). Collaboration encourages equal sharing in children but not in chimpanzees. Nature, 476(7360), 328-331.

Hedtvedt, K. A. (2006). Justice frameworks. P. Burke (Ed.), Contemporary social psychological theories içinde (Cilt 1, s. 46-69). Stanford, CA: Stanford University Press.

Kanngiesser, P. ve Warneken, F. (2012). Young children consider merit when sharing resources with others. PlosOne, 7(8), 1-5.

Katz, J., Demir, N., Önen, F., Uzlukaya, A. ve Uludağ, A. (1972). Türkçe konuşan çocuklar için Peabody Resim Kelime Testi Resim Dizisi (Peabody Picture-Vocabulary Test). Ankara: Ankara Rehberlik ve Araştırma Merkezi. 
LoBue, V., Nishida, T., Chiong, C., DeLoache, J. S. ve Haidt, J. (2011). When getting something good is bad: Even three-year-olds react to inequality. Social Development, 20(1), 154-170.

Loewenstein, G. F., Thompson, L. ve Bazerman, M. H. (1989). Social utility and decision making in interpersonal contexts. Journal of Personality and Social Psychology, 57(3), 426.

McAuliffe, K., Blake, P. R., Kim, G., Wrangham, R. W. ve Warneken, F. (2013). Social influences on inequity aversion in children. PloSone, 8(12), 1-11.

Melis, A. P., Hare, B. ve Tomasello, M. (2006). Engineering cooperation in chimpanzees: Tolerance constraints on cooperation. Animal Behaviour, 72(2), 275-286.

Moore, C. (2009). Fairness in children's resource allocation depends on the recipient. Psychological Science, 20(8), 944-948.

Öner, N. (2006). Türkiye'de kullanılan psikolojik testlerden örnekler. İstanbul: Boğaziçi Üniversitesi Yayınları.

Paulus, M. (2015). Children's inequity aversion depends on culture: A cross-cultural comparison. Journal of Experimental Child Psychology, 132, 240-246.

Piaget, J. (2002). Judgement and reasoning in the child (M. Warden, Çev). Londra: Routledge.

Savaşır, I., Sezgin, N. ve Erol, N. (1992). 0-6 yaş Çocukları için Gelişim Tarama Envanteri geliştirilmesi: Ön çalışmalar. Türk Psikiyatri Dergisi, 3(2), 33-42.

Savaşır, I., Sezgin, N. ve Erol, N. (2006). Ankara Gelişim Tarama Envanteri el kitabı (Düzeltilmiş 4. Bask1) Ankara: Türk Psikologlar Derneği.

Schafer, M., Haun, D. B., ve Tomasello, M. (2015). Fair is not fair everywhere. Psychological Science, 26(8), 1252-1260.

Sheskin, M., Bloom, P. ve Wynn, K. (2014). Anti-equality: Social comparison in young children. Cognition, 130(2), 152-156.

Silk, J. B., Brosnan, S. F., Vonk, J., Henrich, J., Povinelli, D. J., Richardson, A. S., ... ve Schapiro, S. J. (2005). Chimpanzees are indifferent to the welfare of unrelated group members. Nature, 437(7063), 1357-1359.

Steinbeis, N. ve Singer, T. (2013). The effects of social comparison on social emotions and behavior during childhood: The ontogeny of envy and Schadenfreude predicts developmental changes in equity-related decisions. Journal of Experimental Child Psychology, 115(1), 198-209.

Thompson, C., Barresi, J. ve Moore, C. (1997). The development of future-oriented prudence and altruism in preschoolers. Cognitive Development, 12(2), 199-212.

Tomasello, M., Melis, A. P., Tennie, C., Wyman, E.,ve Herrmann, E. (2012). Two key steps in the evolution of human cooperation: The interdependence hypothesis. Current Anthropology, 53(6), 673-692.

Tomasello, M. ve Vaish, A. (2013). Origins of human cooperation and morality. Annual Review of Psychology, 64, 231-255.

Warneken, F., Lohse, K., Melis, A. P. ve Tomasello, M. (2011). Young children share the spoils after collaboration. Psychological Science, 22(2), 267-273.

Williams, A. ve Moore, C. (2014). Exploring disadvantageous inequality aversion in children: How cost and discrepancy influence decision-making. Frontiers in Psychology, 5, 1-6. 
